\title{
2009/14
}

The valuation of power futures

based on optimal dispatch

Gauthier de Maere d'Aertrycke and Yves Smeers 
CORE

Voie du Roman Pays 34

B-1348 Louvain-la-Neuve, Belgium.

Tel (32 10) 474304

Fax (32 10) 474301

E-mail: corestat-library@uclouvain.be http://www.uclouvain.be/en-44508.html 


\title{
CORE DISCUSSION PAPER \\ $2009 / 14$
}

\section{The valuation of power futures based on optimal dispatch}

\section{Gauthier de MAERE d'AERTRYCKE ${ }^{1}$ and Yves SMEERS ${ }^{2}$}

\author{
March 2009
}

\begin{abstract}
The pricing of contingent claims in the wholesale power market is a controversial topic. Important challenges come from the non-storability of electricity and the number of parameters that impact the market. We propose an equilibrium model based on the fundamentals of power generation. In a perfect competitive market, spot electricity prices are determined by the marginal cost of producing the last unit of power. Electricity can be viewed as a derivative of demand, fuels prices and carbon emission price. We extend the Pirrong-Jermakayan model such as to incorporate the main factors driving the marginal cost and the non-linearities of electricity prices with respect to fuels prices. As in the Pirrong-Jermakayan framework, any contingent claims on power must satisfy a high dimensional PDE that embeds a market price of risk, as load is not a traded asset. Analyzing the specificity of the marginal cost in power market, we simplify the problem for evaluating power futures so that it becomes computationally tractable. We test our model on the German EEX for "German Month Futures" with maturity of June and September 2008.
\end{abstract}

Keywords: power contingent claims, PDE valuation of financial derivatives, unit commitment, market price of risk, EEX.

JEL Classification: C61, G13

${ }^{1}$ Université catholique de Louvain, CORE and INMA, B-1348 Louvain-la-Neuve, Belgium.

E-mail: Gauthier.demaere@uclouvain.be

2 Université catholique de Louvain, CORE and INMA, B-1348 Louvain-la-Neuve, Belgium.

E-mail: yves.smeers@uclouvain.be. This author is also member of ECORE, the newly created association between CORE and ECARES

This research was supported by a grant from GDF-Suez. We thank Dr. Andreas Ehrenmann, Pr. Pierre Devolder and Pr. Vincent Legat for all suggestions and the useful comments on the subject.

This paper presents research results of the Belgian Program on Interuniversity Poles of Attraction initiated by the Belgian State, Prime Minister's Office, Science Policy Programming. The scientific responsibility is assumed by the authors. 



\section{Introduction}

The volume of power contracts and their derivatives traded on Power Exchanges has been growing since the beginning of the restructuring of the electricity sector. A common approach for pricing contingent claim on a stock in finance is to assume an affine diffusion process for this stock's value. It is then possible to form a riskfree portfolio by combining the contingent claim and the stock. Non-arbitrage condition implies then a unique price for the contingent claim. A contingent claim on a commodity is not the same as a contingent claim on a stock. The commodity implies a physical delivery. Nevertheless, one can still obtain a relationship between the commodity spot $S(t)$ and the price of the contingent claim. A valuation is possible by assuming a commodity's storage cost. The most famous example is the pricing of a future $F(t, T)$ at time $t$ expiring at $T$ by the cost-of-carry relationship:

$$
F(t, T)=S(t) e^{[r(t)+c(t)](T-t)}
$$

where $r(t)$ is the riskfree interest rates and $c(t)$ is the marginal cost of storage.

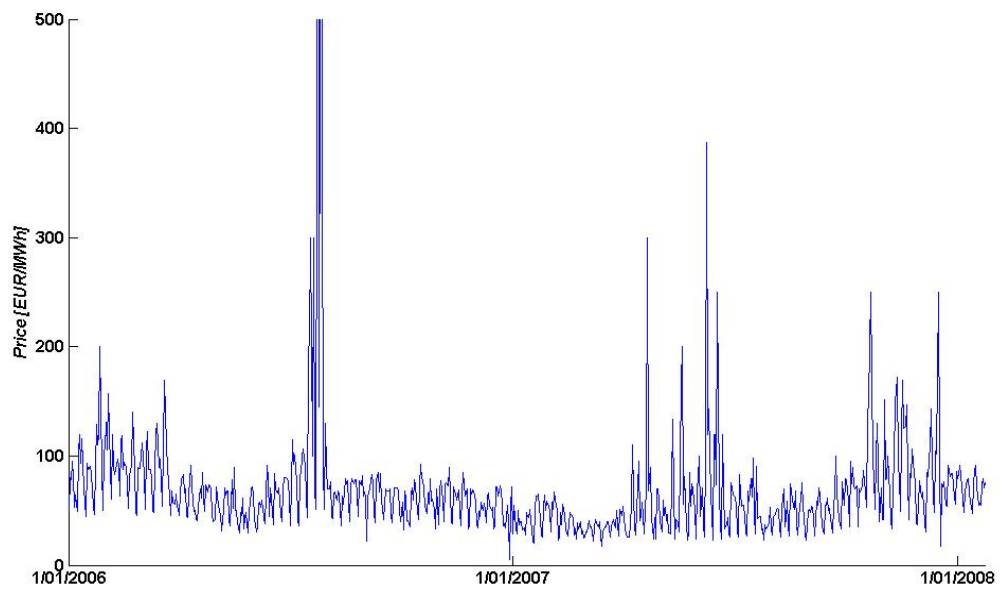

Figure 1: German electricity spot price [ $€ / \mathrm{MWh}]$ at 12:00am on the EEX

None of these approaches is applicable in electricity because it is a non storable commodity. One cannot buy power on the spot (day-ahead) market, store it and re-sell it later. This specificity implies a prices dynamic that spikes to extremely high value ${ }^{1}$. These jumps usually occur within a very short period of time. Figure (1) shows the evolution of the peak electricity price on the European Energy Exchange (EEX) in the

\footnotetext{
${ }^{1}$ For example, the 27 July 2005 , electricity price reached the extreme value of $2000 € /$ MWh at 12 am on the EEX
} 
day-ahead German spot market ${ }^{2}$ at 12:00 am from 2006 to 2008. Besides spikes, a second important feature of electricity price time series is their strong seasonal character, mainly due to the time varying demand. Seasonal variations appear as well within a day, as within a month, or over the year.

In recent years, researchers have developped a variety of derivative pricing models for electricity by estimating stochastic process for the spot prices that captures the above mentioned charateristics. For example, Schwartz and Smith (2000) and Lucia and Schwartz (2002) implemented a two factors model that exhibit mean-reversion in the short-term dynamics. Geman and Roncoroni (2006) and Villaplana (2003) captured the non-linearities of the spot price mechanism by using jump diffusion models component to the stochastic process. Finally, regime switching has been introduced recently (e.g. Huisman and Mahieu (2003) and Bloechlinger (2006)). A more complete presentation of all those models and a comparison of their performances for the EEX market can be found in Bierbrauer et al. (2007).

One can improve one's understanding of electricity prices by including state variables that are closely linked to the supply and demand. Other researchers have explored those so-called equilibrium based models. For example, Bessembinder and Lemmon (2002) assumed that the prices are determined by the market participants (producers and retailers) rather than by a speculation mechanism. They derived the forward market equilibrium, assuming symmetric producers with risk averse utility function, and symmetric convex production function. On an econometric perspective, Cartea and Villaplana (2007) studied the dynamics of spot prices, estimating a model containing two explanatory variables, one associated with the supply state namely the reserve capacity , and the other representing the demand. Those variables are not traded on the market, so the valuation of a contingent claim contains a risk premium. Pirrong and Jermakyan (2000) implemented a model where the spot price is written as a function of 2 state variables, demand and the marginal fuel. They derived the PDE that power derivatives must satisfy. As demand is not traded, its risk neutral dynamics contains a market price of risk that is reflected in the PDE. They evaluated this market price of risk using inverse problem's techniques.

Our model is based on the Pirrong and Jermakyan (2000) framework. These authors assume the existence of a fuel that always set the price and so is marginal for every hour. In most markets, there exist a technology mix between nuclear, gas, coal and renewable energy. No fuel remain marginal all the time. Roughly speaking, gas is the marginal fuel during the peak hours, whereas coal is marginal during off-peak (even if the situation is more complex since 2007 because of the continuing increase of coal prices). In European countries, power prices are also affected by carbon EU emission allowances. The major difficulty is to predict the influence of all these factors on electricity prices. As the number of factors is important and their effects on electricity are non-linear, we do not consider an econometrics approach but rather develop a model of a perfectly competitive market. The price of the electricity is then equal to the variable cost of the marginal generating unit which is itself determined by the stochastic evolution of physical factors. This variable

\footnotetext{
${ }^{2}$ On the hourly day-ahead market, power is traded for physical delivery the next day. It is based on an auction with bids for purchase and sale of power contracts of one hour duration.
} 
cost indeed depends principally on generators characteristics, such as demand and fuel and carbon emission prices. Some generators characteristics (i.e., capacity, efficiency and carbon emission rate) remain constant over time but others like availability changes over the year due to maintenance or unplanned outage. Total capacity is assumed to be known in advance in our model, so the marginal cost varies essentially with demand, fuels and carbon cost. Figure (2) shows such a marginal cost curve, constructed using month fuels and carbon futures with maturity of September. One can see on this picture how the equilibrium changes with fuels and carbon futures and the non-linearity of the marginal curve with respect to the fuels and carbon futures.
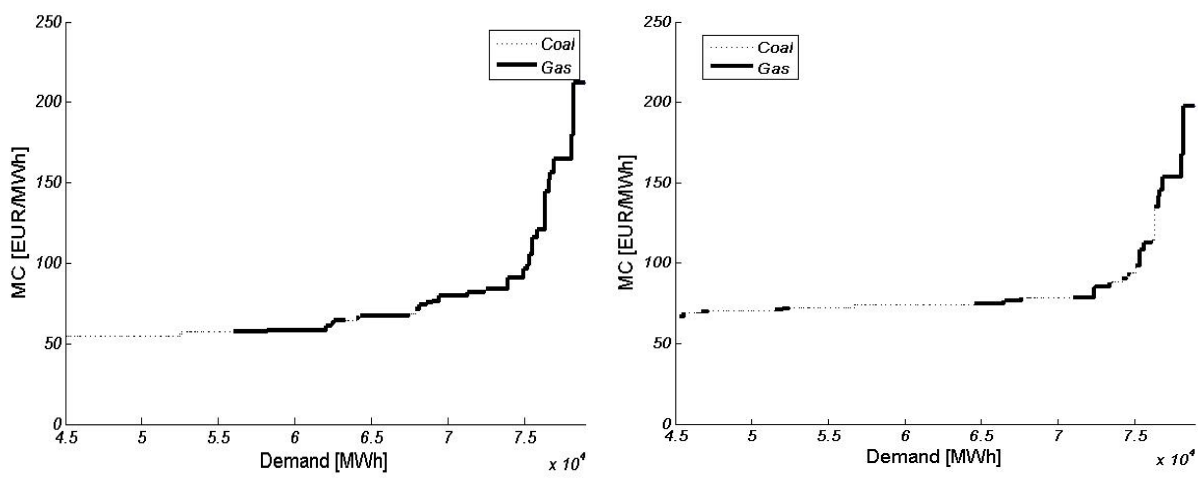

Figure 2: Marginal cost curve the 3 April 2008 (right) and the 28 August 2008 (left) using fuels and carbon futures with maturity of September

This marginal cost approach is probably the most used used for market simulation, as well by regulators, as by researchers in the litterature on market power (e.g.Musgens (2006) or Borenstein et al. (2002)), as in the forecasting of electric energy prices. Our model derives the financial mathematic's implications of this marginal-cost pricing for the valuation of power contingent claims.

The paper is organized as follow. Section 2 extend the Pirrong-Jermakayan equilibriummodel of power derivative pricing to include more explanatory variables. Section 3 analyzes the marginal-cost pricing process. It shows that the merit order curve can be fully characterized by a dimensionless parameter. This allows one to simplify the PDE for the valuation of the futures. The PDE obtained is computationally tractable. It depends on the load, the time to maturity and two new dimensionless parameters. In section 4 , we first discuss the estimation of the stochastic process. Then the calibration procedure to obtain the market price of risk is presented. We also show the results of the model for pricing Month Futures on the European Energy Exchange (EEX). We conclude the paper in section 5 . 


\section{The model}

We model the behavior of power contingent claims by assuming that the spot price is determined by different explanatory variables. The first one is the domestic load satisfied by thermal generators. It is equal to the domestic demand from which we subtract the the non-thermal production( i.e., run of river hydro, wind turbine,...) and import-export flows through the interconnectors. For each month, the shape of this load is almost the same for every working day (see Figure 3) and seems just translated vertically according to the value of the peak.

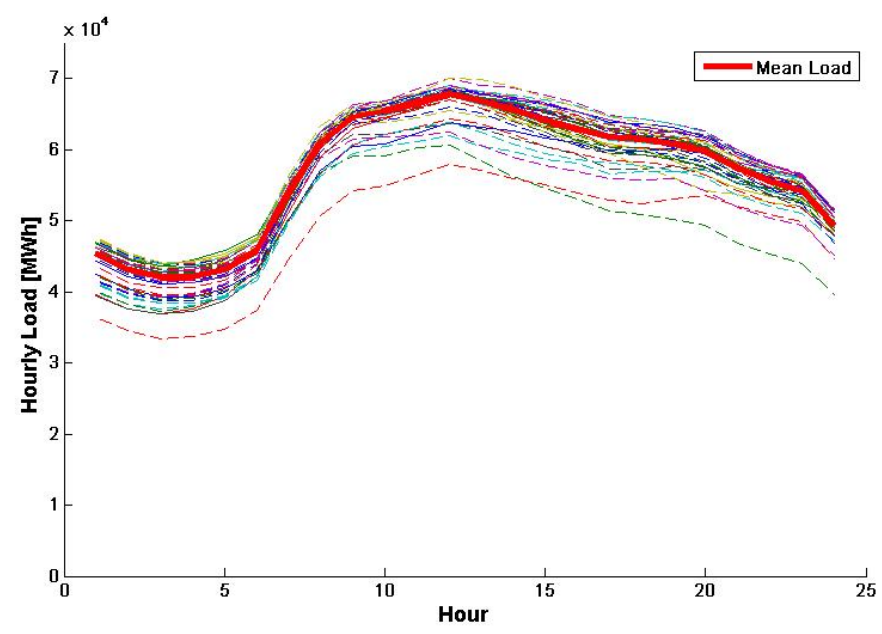

Figure 3: Hourly load shape for the weekdays of June during 2006-2007 in Germany

We accordingly consider a stochastic process describing the evolution of the load $q_{t}$ at the peak (value at 12am) and assume a constant load shape for each month. The peak load process is seasonal. For a central West European country, it achieves its highest value during winter months and exhibits strong reversion to a seasonal mean. We model it by a geometric time-varying mean-reverting process:

$$
\frac{d q_{t}}{q_{t}}=k\left(\ln \left(q_{t}\right)-\theta_{q}(t)\right) d t+\sigma_{q} d u_{t}-d L_{t}^{u}+d L_{t}^{l}
$$

In this stochastic differential equation (SDE) the function $\theta_{q}(t)$ is the logarithm of the predictable trend around which the load process fluctuates. The negative parameter $k$ is the average variation of the load per unit of shift away from the seasonal trend. It measures the speed of the mean reversion. For simplicity of notation define $\alpha_{q}$, the non-stochastic part of the SDE.

$$
\alpha_{q}(q, t)=k\left(\ln \left(q_{t}\right)-\theta_{q}(t)\right)
$$

The Brownian motion $d u_{t}$ is the source of randomness of the load, the constant $\sigma$ is the volatility associated with the Brownian motion. The processes $d L_{t}^{u}$ and $d L_{t}^{l}$ are 
control processes and keep the load below the maximal capacity $u$ and above a minimal capacity $l$. Under technical conditions ${ }^{3}$, Harrison and Taksar (1983) show that the stochastic process will exhibit reflection at $u$ and $l$. So, $d L_{t}^{u}$ is positive when the load exceeds the maximal capacity and $d L_{t}^{l}$ is positive when the load falls below the limit $l$. Those processes are equal to zero otherwise. They are called the local time of the load at the boundary.

The second and the third explanatory variables are two fuels $f^{(1)}$ and $f^{(2)}$. The selection of the fuels depends on the market studied, and one should choose fuels that are effectively marginal fuels during the day, depending on the level of the demand. For example, in most country gas and coal are the usual two marginal fuels.

The time dynamics of power contingent claim at time $t$ for maturity $T$ depends on the futures of the marginal fuels that achieves maturity at the same time $T$. The processes for the marginals futures fuels are supposed to be the following affine diffusion processes.

$$
\frac{d f_{t, T}^{(1)}}{f_{t, T}^{(1)}}=\alpha_{1}\left(f_{t, T}^{(1)}, t\right) d t+\sigma_{1} d v_{t} ; \quad \frac{d f_{t, T}^{(2)}}{f_{t, T}^{(2)}}=\alpha_{2}\left(f_{t, T}^{(2)}, t\right) d t+\sigma_{2} d w_{t}
$$

In those SDE's, $d v_{t}$ and $d w_{t}$ are Brownian motions with constant volatility $\sigma_{1}$ and $\sigma_{2}$. We assume, as it is the case in most markets, that the fuels processes are not correlated to the load, even though they can be correlated to each other, so $d v_{t} d w_{t}=\rho_{12} d t$.

Our last explanatory variables is the price of carbon emission $\mathbf{f}^{(\mathbf{3})}$. European authorities, concerned about climate change, introduced a carbon market (EU ETS) whereby power companies need to compensate for their $\mathrm{CO}_{2}$ emissions by submitting equivalent amounts of allowances. The nowadays fluctuating carbon price (around 23 [€/Ton]) is an important driving factor of the electricity price. As fuel futures, the EU carbon futures are modeled by an affine diffusion process.

$$
\frac{d f_{t, T}^{(3)}}{f_{t, T}^{(3)}}=\alpha_{3}\left(f_{t, T}^{(3)}, t\right) d t+\sigma_{3} d x_{t}
$$

The process $d x_{t}$ is a Brownian motion with constant volatility $\sigma_{3}$, carrying the uncertainty of carbon price. This Brownian motion is assumed to be uncorrelated to the Brownian motions of the other explanatory variables. This is definitely a simplifying assumption as the relative prices of coal and gas are important ( but still poorly understood) determinants of $\mathrm{CO}_{2}$ prices.

\footnotetext{
${ }^{3}$ The controller processes $d L_{t}$ can change instantaneously the level of $\mathrm{q}$ and the pushing rates are unbounded. There exist then an optimal control policy that keeps the load between the lower bound $l$ and the upper bound $u$.
} 


\section{Risk neutral dynamics}

The fundamental theorem of asset pricing in Finance comes from the principle of absence of arbitrage opportunities ${ }^{4}$. Assuming that there is no arbitrage opportunities, then there exist a risk-neutral probability measure $\mathcal{Q}$ under which all discounted assets and contingent claims are martingales ${ }^{5}$. This risk-neutral measure is unique if and only if every contingent claim can be perfectly hedged.

The pay-off of a contingent claim $C$ based on electricity is known at maturity. We assume that the spot price at maturity is given by the marginal cost $\mathbf{M C}$ (the form of this marginal cost is explained in the next section), and so at maturity, the pay-off of $C$ is a function $h$ of this marginal $\operatorname{cost}^{6}$.

$$
C_{T}=h\left(\mathbf{M C}\left(q, f^{(1)}, f^{(2)}, f^{(3)}, T\right), T\right)
$$

As a power contingent claim is traded on the market, its dynamics under $\mathcal{Q}$ is a martingale:

$$
\frac{C_{t}}{\beta(t)}=\mathbb{E}_{\mathcal{Q}}\left[\frac{1}{\beta(T)} h\left(\mathbf{M C}\left(q, f^{(1)}, f^{(2)}, f^{(3)}, \mathrm{T}\right), T\right) \mid \mathcal{C}_{t}\right]
$$

To evaluate this expression, we should know the risk-neutral dynamics of the explanatory variables. The dynamics of the futures are $\mathcal{Q}$-martingales as these are also traded. So the risk neutral processes of the fuels and EU carbon futures are:

$$
\frac{d f^{(1)}}{f^{(1)}}=\sigma_{1} d \tilde{v}_{t} \quad, \frac{d f^{(2)}}{f^{(2)}}=\sigma_{2} d \tilde{w}_{t} \quad, \frac{d f^{(3)}}{f^{(3)}}=\sigma_{3} d \tilde{x}_{t}
$$

where the terms $d \tilde{v}_{t}, d \tilde{w}_{t}$ and $d \tilde{x}_{t}$ are $\mathcal{Q}$ Brownian motions.

The load dynamics under $\mathcal{Q}$ is more unusual. First of all, the load stochastic process contains control processes under the true probability measure $\mathcal{P}$. But, as $\mathcal{P}$ and $\mathcal{Q}$ must share sets of measure zero, the load stochastic process $q_{t}$ should exhibit reflection at the boundaries $l$ and $u$. It dynamics under $\mathcal{Q}$ contains also the two control processes. More importantly, load is not a traded asset, the arbitrage-free condition does impose its dynamics. We suppose w.l.o.g. that the Brownian motion $d u_{t}$ becomes $d u_{t}=d \tilde{u}_{t}-\lambda(q, t)$ under $\mathcal{Q}$, where $\lambda$ can be any function of $t$ and $q$ :

$$
\frac{d q_{t}}{q_{t}}=\left[-\sigma_{q} \lambda(q, t)+k\left(\ln \left(q_{t}\right)-\theta_{q}(t)\right)\right] d t+\sigma_{q} d \tilde{u}_{t}-d L_{t}^{u}+d L_{t}^{l}
$$

This dynamics includes a market price of risk function $\lambda$. The risk-neutral measure for our market model is not unique. There can be several risk function because power contingent claims depending on the stochastic and not traded load, are hence not hedgeable.

\footnotetext{
${ }^{4}$ Notice that in continuous time, the no-arbitrage condition is not strict enough and further requirements have to be put on the portfolios to establish a version of a fundamental theorem of asset pricing. Those requirements are known as the No Free Lunch with Vanishing Risk (NFLVR) condition)

${ }^{5}$ Note that futures does not have to be discounted as the payment is due at maturity. Under $\mathcal{Q}$ their process have just to be a martingale.

${ }^{6}$ For example, $h=(\mathbf{M C}-K)^{+}$for an option
} 
The market should give the incentive to the seller to take this risk. The function $\lambda$ depends on the market and has to be estimated from the market data ${ }^{7}$.

\section{The fundamental valuation PDE}

Equation (7) does not lead to an analytical expression for the valuation of the power contingent claim. Indeed, the determination of the marginal cost is not amenable to an analytical function but is given by the solution of an optimization problem (see next section). Also, the process $d L_{t}^{u}$ and $d L_{t}^{l}$ makes the derivation of the $\mathcal{Q}$-expectation of $C$ unusual.

Researchers (Pirrong and Jermakyan (2000),Farnsworth and Bass (2003)) have studied pricing with reflecting process. Under $\mathcal{Q}$, the dynamics of a contingent claim is a martingale. The evolution of contingent claim should solve a partial differential equation. Extending the Pirrong-Jermakayan's framework with our additional variables and changing the time variable by $\tau=T-t$, one can derive the following PDE that any power contingent claim $C$ must satisfy.

$$
\begin{aligned}
\frac{\partial C}{\partial \tau}=\quad & -r C+\frac{\partial C}{\partial q}\left[\alpha_{q}(q, \tau)-\sigma_{q} \lambda(q, t)\right] q+\frac{1}{2} q^{2} \sigma_{q}^{2} \frac{\partial^{2} C}{\partial q^{2}} \\
& +\frac{1}{2}\left(f^{(1)}\right)^{2} \sigma_{1}^{2} \frac{\partial^{2} C}{\partial\left(f^{(1)}\right)^{2}}+\frac{1}{2}\left(f^{(2)}\right)^{2} \sigma_{2}^{2} \frac{\partial^{2} C}{\partial\left(f^{(2)}\right)^{2}} \\
& +\rho_{12}\left(f^{(1)} f^{(2)} \sigma_{1} \sigma_{2}\right) \frac{\partial^{2} C}{\partial f^{(1)} \partial f^{(2)}}+\frac{1}{2}\left(f^{(3)}\right)^{2} \sigma_{3}^{2} \frac{\partial^{2} C}{\partial\left(f^{(3)}\right)^{2}} \\
\text { s.t: } \quad & \left.\frac{\partial C}{\partial q}\right|_{q=U}=0 \\
& \left.\frac{\partial C}{\partial q}\right|_{q=L}=0 \\
& C_{T}=h\left(\mathbf{M C}\left(q, f^{(1)}, f^{(2)}, f^{(3)}, T\right), T\right)
\end{aligned}
$$

Applying this equation to a futures contract, we get:

$$
\begin{aligned}
\frac{\partial F}{\partial \tau}=\quad & \frac{\partial F}{\partial q}\left[\alpha_{q}(q, \tau)-\sigma_{q} \lambda(q, t)\right] q+\frac{1}{2} q^{2} \sigma_{q}^{2} \frac{\partial^{2} F}{\partial q^{2}} \\
& +\frac{1}{2}\left(f^{(1)}\right)^{2} \sigma_{1}^{2} \frac{\partial^{2} F}{\partial\left(f^{(1)}\right)^{2}}+\frac{1}{2}\left(f^{(2)}\right)^{2} \sigma_{2}^{2} \frac{\partial^{2} F}{\partial\left(f^{(2)}\right)^{2}} \\
& +\rho_{12}\left(f^{(1)} f^{(2)} \sigma_{1} \sigma_{2}\right) \frac{\partial^{2} C}{\partial f^{(1)} \partial f^{(2)}}+\frac{1}{2}\left(f^{(3)}\right)^{2} \sigma_{3}^{2} \frac{\partial^{2} F}{\partial\left(f^{(3)}\right)^{2}} \\
\text { s.t: } \quad & \left.\frac{\partial F}{\partial q}\right|_{q=X}=0 \\
& \left.\frac{\partial F}{\partial q}\right|_{q=L}=0 \\
& F_{T, T}=\mathbf{M C}\left(q, f^{(1)}, f^{(2)}, f^{(3)}, \mathrm{T}\right)
\end{aligned}
$$

\footnotetext{
${ }^{7}$ Pirrong and Jermakyan (2000) assume that this function is only function of the load $\lambda=\lambda\left(q_{t}\right)$ and estimated it using inverse problem techniques
} 
The resolution of the PDE (10) or (11) is computationally time demanding. It has to be solved in 5 dimensions (i.e. time, load and the 3 futures). We describe the computation of the marginal cost in the next section and propose a simplification of the PDE (11) for future contract.

\section{Unit Commitment and initial conditions}

Assuming a perfectly competitive market, the spot price of the electricity should be find by the usual intersection of the supply marginal cost and demand bids. For electricity, demand is inelastic in the short-run, and so price is simply the variable marginal cost to meet the demand. We construct this price, assuming a very simplified market where the generators are perfectly dispatchable (i.e. have convex production set). We capture the non deterministic production of the the wind and run-of-river hydro by subtracting them from the load and so incorporate them into the stochastic process of the load. We consider storage hydro generation by adding pumping and total storage hydro capacity. Daily prices can be found by solving the following daily "Unit Commitment" problem.

$$
\begin{aligned}
z^{*}= & \min _{q_{i, h}} \sum_{i, h} \mathrm{MC}_{i} q_{i, h} \\
\text { s.t. } & 0 \leq q_{i, h} \leq K_{i} \\
& \sum_{h} q_{i, h}=\operatorname{Load}_{h}+\operatorname{pump}_{h} \\
& \sum_{h}^{h}\left(q_{\text {hydro }, h}-\eta \operatorname{pump}_{h}\right) \leq 0
\end{aligned}
$$

In problem (12), the spot hourly price $S(t)$ is given by the dual variable of the demand constraint. We assume that the spot price is set at $1000[€ / \mathrm{MWh}]$ by the TSO regulator when the total capacity is saturated. This recourse to a Value Of Loss Load (VOLL) hypothesis permits us to capture the spikes in the spot process. Those spikes, which are due to the non-storability of electricity, are an important risk related to the load. So the reflected process $d L_{t}^{u}$ is active for a demand value slightly higher than the total capacity of the power generation system.

The marginal cost pricing contains several shortening (Scott and Hogan, 2002). We are excluding some important features of power generation such as operating reserve requirement, minimum running time and the minimum load constraint of generators, start-up cost for a cold start or warm start,... All those constraints makes the Unit Commitment problem non convex, so it is not anymore possible to find linear prices that supports the dispatch solution. Considerable research is conducted on spot market prices in order to capture the effect of those non-convexities and some argue (Gribik et al., 2007) that other price mechanism (i.e. non linear pricing) have to be implemented. Nevertheless, we rely on the simple dispatch model because it already capture a significant part of spot price evolution and is much simpler to compute. We leave it to further research to explore more complex pricing mechanism. 


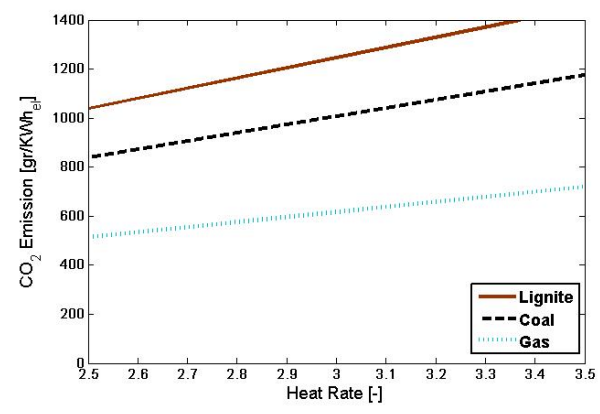

Figure 4: Emission rate vs heat rate for different technologies

The marginal cost of the generator $i$ depends on its technology. It is equal to its unit fuel cost $\eta_{i} f^{(i)}$ (for producing one MWh of electricity) plus the allowance cost of the carbon emitted. The $\mathrm{CO}_{2}$ emission of a power plant using the fuel $f^{(i)}$ is approximately a linear function of the heat rate (see figure (4) ). So, its marginal cost is linear in the fuel and carbon prices and has the following structure:

$$
M C_{i}=\eta_{i}\left(f^{(i)}+c_{(f)} f^{(3)}\right)
$$

We consider a market where only 2 technologies, using fuel $f^{(1)}$ and $f^{(2)}$, can be marginal ${ }^{8}$. The simplified "Unit Commitment" problem is then a linear optimization problem. One can normalize the objective's vector by dividing the marginal cost of all different units by $\left(f^{(2)}+c_{2} f^{(3)}\right)$ without changing the optimal quantities $q_{i, h}^{*}$. We thus restate the optimal dispatch problem as:

$$
\begin{aligned}
z^{\prime}= & \min _{q_{i, h}} \sum_{i, h} \eta_{i} \frac{f^{(i)}+c_{(f)} f^{(3)}}{f^{(2)}+c_{2} f^{(3)}} q_{i, h} \\
\text { s.t. } & 0 \leq q_{i, h} \leq K_{i} \\
& \sum_{h} q_{i, h}=\operatorname{Load}_{h}+\operatorname{pump}_{h} \\
& \sum_{h}\left(q_{\text {hydro }, h}-\eta \operatorname{pump}_{h}\right) \leq 0
\end{aligned}
$$

The new objective vector in problem (14) is dimensionless and its dual variables associated with the demand constraint give the electricity prices divided by $\left(f^{(2)}+c_{2} f^{(3)}\right)$. As only technologies using fuel $f^{(1)}$ and $f^{(2)}$ can set the price, the optimal solution of problem (14) are only determined by the dimensionless parameter $\gamma=\frac{f_{1}+c_{1} f_{3}}{f_{2}+c_{2} f_{3}}$. For example, the merit order is unchanged for 2 situations with different fuel cost but the same $\gamma$. The shape of the marginal cost curve is the same.

\footnotetext{
${ }^{8}$ Usually, units with low marginal cost, such as lignite or nuclear, do not have enough capacity to meet all the demand.
} 

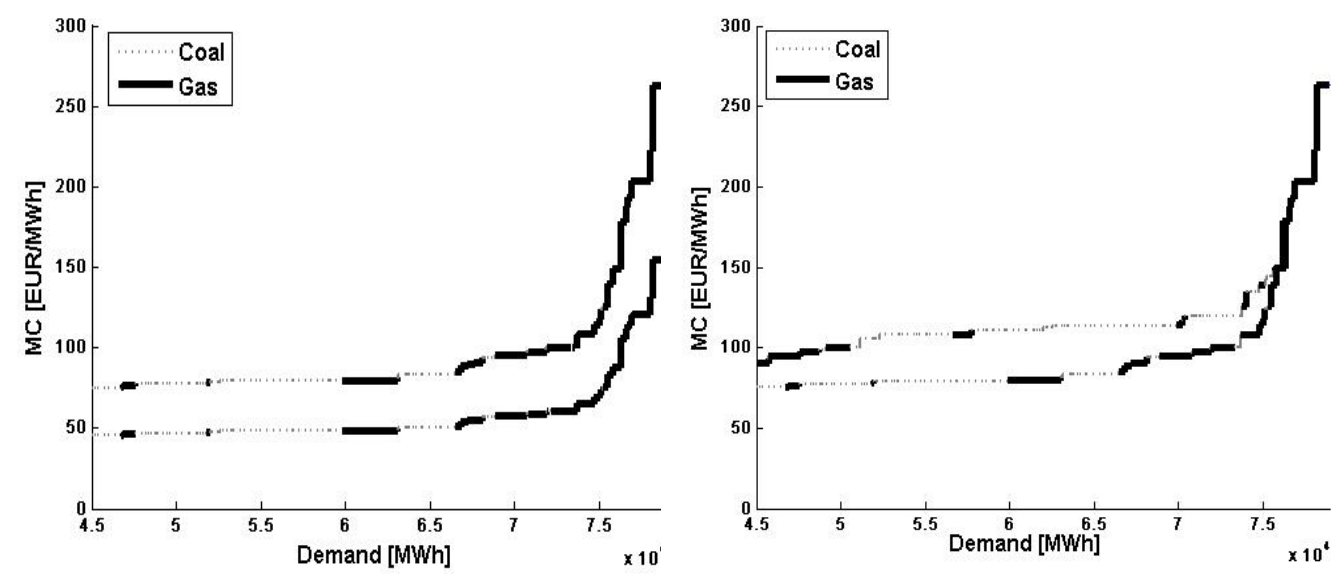

Figure 5: Merit order curve for different fuel scenarios, with the same $\gamma$ (left) and with 2 different $\gamma$ (right)

Knowing $\gamma$ is sufficient to determine which power plant is marginal for a certain demand. The marginal cost process $\mathbf{M C}$ can thus be written in the form :

$$
\mathbf{M C}=\alpha(q, \gamma)\left(f^{(2)}+c_{2} f^{(3)}\right)
$$

Taking account of that particular structure of the future pay-off in a competitive market, we try a solution of the futures valuation PDE with this particular form.

$$
F=g(q, \tau, \gamma)\left(f^{(2)}+c_{2} f^{(3)}\right)
$$

The former futures PDE (11) can be reformulated for the $g$ function in the variable $\gamma$ and using a new adimensional number ${ }^{9} \zeta=\frac{c_{1} f^{(3)}}{\left(f^{(2)}+c_{2} f^{(3)}\right)}$

$$
\begin{aligned}
\frac{\partial g}{\partial \tau}= & \frac{\partial g}{\partial q_{t}}\left[\alpha_{q}\left(q_{t}, t\right)-\sigma_{q} \lambda(q, t)\right] q_{t}+\frac{1}{2} q_{t}^{2} \sigma_{q}^{2} \frac{\partial^{2} g}{\partial q_{t}^{2}} \\
& +\frac{\sigma_{1}^{2}}{2}(\gamma-\zeta)^{2} \frac{\partial^{2} g}{\partial \gamma^{2}} \\
& +\frac{\sigma_{2}^{2}}{2}\left(1-\frac{c_{2}}{c_{1}} \zeta\right)^{2} \gamma^{2} \frac{\partial^{2} g}{\partial \gamma^{2}} \\
& -\rho_{12}\left(\sigma_{1} \sigma_{2}\right) \gamma\left(1-\frac{c_{2}}{c_{1}} \zeta\right)(\gamma-\zeta) \frac{\partial^{2} g}{\partial \gamma^{2}} \\
& +\frac{\sigma_{3}^{2}}{2} \zeta^{2}\left(1-\frac{c_{2}}{c_{1}} \gamma\right)^{2} \frac{\partial^{2} g}{\partial \gamma^{2}}
\end{aligned}
$$

This partial differential equation (15) contains 4 dimensions: the time to maturity $\tau$, the load $q$ and the dimensionless numbers $\gamma$ and $\zeta$. To solve numerically the futures valuation problem, one should first create a mesh $q$ and $\gamma$, then run the Unit Commitment

\footnotetext{
${ }^{9}$ The nature of $\zeta$ is different than $\gamma$. It appears technically because we choose a geometric Brownian motion for modeling fuels and carbon futures dynamic.
} 
problem in order to get the pay-off of the future for all the point in the mesh. Then, by dividing the price by $\left(f_{2}+c_{2} f_{3}\right)$, one gets the initial condition for the function $g$. Then, if $\lambda$ is known, one can find the price of the futures at time $t$ by solving numerically the 3 -dimensional equation (15) for $g$ with the actual value of the variable $\zeta$. Finally, the price of the future is given by $F_{t, T}=g\left(\gamma, q_{t}, \tau\right)\left(f_{2}+c_{2} f_{3}\right)$.

The remaining challenge is to estimate the $\lambda$ function from the market data. We explain in the next section the numerical procedure to calibrate this function and obtain the solution.

\section{Results}

We test the model on "German Month futures" which are contracts traded on EEX. The buyer of such contract has to consume one MWh of electricity (every hour for the BaseLoad contract, and from 08:00 am until 08:00 pm for the PeakLoad,) during all working days of a specified month. The price of this contract refers to the average price that the consumer has to pay for each MWh of electricity. In our model, as the load dynamic is described on a daily basis, we decompose the month future $M(t, T)$ by the average of $N$ daily futures $F(t, T)$ covering the same period.

$$
M_{t, \tau}=\frac{1}{N} \sum_{i=0}^{N-1} F_{\tau+i}
$$

We present in this section the solution procedure for the German Month futures with maturity September 2008.

\section{Estimation of the stochastic processes}

As mentioned before, we assume a constant hourly load shape for every working days of a month. The stochastic process $q_{t}$ refers to the peak load value during those working day. The associated SDE (2) is a geometric Ornstein-Ulhenbeck with time-varying parameter. The parameter $\theta_{q}(t)$ is the expected value of the logarithm of the load $\mathbb{E}\left[\ln \left(q_{t}\right) \mid t\right]$. We use non-parametric smoothing method (local polynomials) to estimate $\theta_{q}(t)$ and capture the deterministic seasonality of the load during the year. We describes in appendix A the actual procedure to obtain the parameters of the load process. We find a speed of mean reversion $\widehat{k}=-0.5088$ which indicates extremely rapid reversal of load shocks. The load variance is equal to $\widehat{\sigma}_{q}^{2}=0.00155$, giving an unconditional variance $-\widehat{\sigma}_{q} / 2 \widehat{k}=0.00152$.

We choose ARA coal futures for the explanatory variable $f^{(1)}$ and EGT gas futures for $f^{(2)}$. The variable $f^{(3)}$ is the European carbon futures for the second compliance period of the EU-ETS(2008-2012). The fundamental PDE (10) for the valuation of a power contingent claims depends on the volatility of those futures. This dependence is due to the non-linearity of the marginal cost process with respect to the fuel and carbon costs. To estimate those volatilities, we assume that their futures processes are geometric Brownian motion with constant drift. Table (4) shows the volatility of the different 
futures with maturity of September 2008.

\begin{tabular}{|c|c|}
\hline & Volatility $\sigma^{2}\left(\times 10^{-4}\right)$ \\
\hline \hline Coal $\left(\sigma_{1}^{2}\right)$ & 4.3809 \\
Gas $\left(\sigma_{2}^{2}\right)$ & 4.3665 \\
Carbon $\left(\sigma_{3}^{2}\right)$ & 3.697 \\
\hline
\end{tabular}

Table 1: Volatility of futures with maturity September 2008

\section{Numerical dicretization}

We solve the PDE using finite differences and Cranck-Nicholson scheme for time marching. The mesh contains 2 dimensions: $\gamma$ and $q$. The PeakLoad value $q$ is discretized uniformly in the interval $[53200,81700]$ MWh using a step of $500 \mathrm{MWh}$. The lower bound is set to $53200 \mathrm{MWh}$, a value sufficiently lower than actual peak load values. This choice is made in order to restrict the computational mesh ${ }^{10}$. The upper bound of $81700 \mathrm{MWh}$ corresponds to a value slightly higher than the maximum capacity of the German generating system during September 2008. At that demand level, the system price reaches the VOLL. As we assume that the load is reflected at those bounds, the boundary conditions for the future valuation problem are:

$$
\left.\frac{\partial g}{\partial q}\right|_{q=L, q=U}=0
$$

The variable $\gamma$ can a priory take an arbitrary value inside $[0, \infty[$. We truncate the problem by disctretizing it in the interval $[0.3,3.23]$. Roughly speaking, those bounds correspond to a point where the marginal cost of a gas power plant is on average 3 times lower ( larger for the lower $\gamma$-bounds) than a coal power plant. Those values have never been seen on the market. As $\gamma$ is a fraction, we use a geometric adaptive step for the dicretization with ratio 1.05. Our model, a usual Feynman-Kac PDE, does not provide any explicit information about the boundary condition in $\gamma$-dimension. We choose to impose a numerical boundary condition which is basically a linear extrapolation of $g$.

$$
\frac{\partial^{2} g}{\partial \gamma^{2}}=0
$$

We tested that errors introduced by the choice of the bounds (which imply a linear behavior of g) are negligible.

We use a second order dicretization scheme for the derivative in $q$ and a third order for $\gamma$. We use the stable Crank-Nicholson scheme for the time marching with a time step equal to $d t=0.1$ day.

\footnotetext{
${ }^{10}$ We tested the solution for different lower bond value. The truncation error due to our choice of the lower bound is not significant for the solution of $g$
} 


\section{Initial conditions}

In order to obtain the initial conditions $g\left(q_{t}, \gamma, \tau=0\right)$ of the PDE (15), we calibrate the simplified Unit Commitment model for September 2008 on the German market ${ }^{11}$ Table 2 gives the maximum capacity per technology for September 2008.

\begin{tabular}{|c|c|}
\hline Technology & Availability (MWh) \\
\hline \hline Nuclear & 14928 \\
Lignite & 15775 \\
Hard Coal & 24076 \\
Gas & 18326 \\
Oil & 3121 \\
Hydro (run of river) & 661 \\
Others & 996 \\
\hline
\end{tabular}

Table 2: Availability in [MWh] for June 2008

We simulate the hourly production and spot prices for the different values of $q$ and $\gamma$ . Then we compute the average marginal $\operatorname{cost}^{12}$, that represents the pay-off of the future and divide it by $\left(f_{2}+c_{2} f_{3}\right)$. Figure (6) shows the initial conditions for the valuation of a PeakLoad contract with maturity of September 2008. One can clearly see that these initial conditions are linear neither in the $q$ nor in the $\gamma$-dimension.

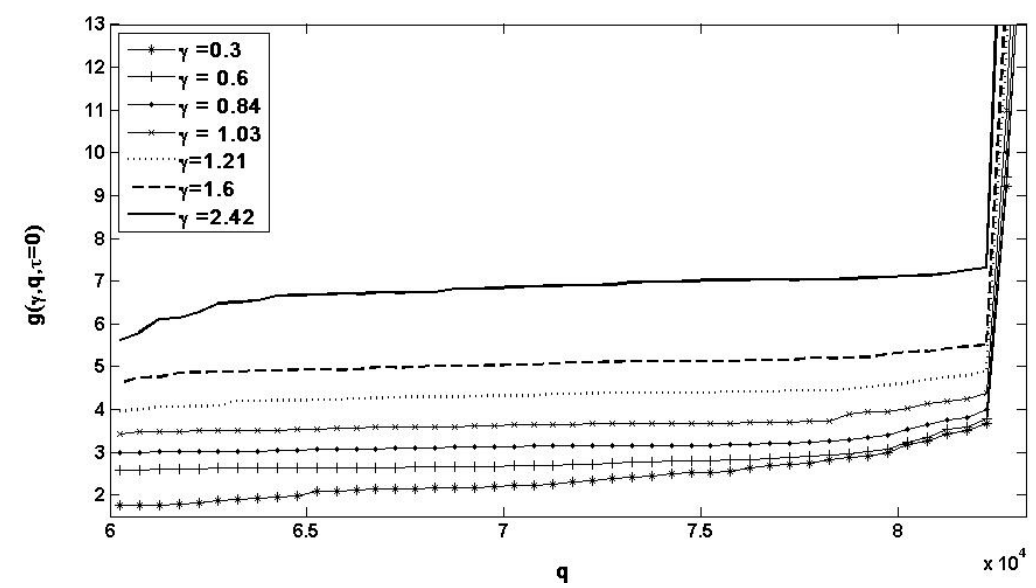

Figure 6: Initial conditions: dimensionless maginal curves $g(q, \gamma, \tau=0)$ for different value of $\gamma$

\footnotetext{
${ }^{11}$ Technical data's on power plant are available in Swider et al. (2007) and the EEX website (www.eex.com).

${ }^{12}$ The average is made on the whole day for a BaseLoad contract, or from 08:00 am until 08:00 pm for a PeakLoad contract
} 


\section{Estimation of the market price of risk}

Finally, the market price of risk $\lambda$ has to be estimated. One should find the function $\lambda$ that minimizes the $L^{2}$ norm of the error, i.e. the difference between model predictions $\mathcal{F}_{i}(\lambda)$ and actual market values $\bar{f}_{i}$.

$$
\lambda^{*} \rightarrow \min _{\lambda} \sum_{i}\left(\mathcal{F}_{i}(\lambda)-\bar{f}_{i}\right)^{2}
$$

The identification of parameters from observations resulting of the evolution of a system is an inverse problem. It does not fulfill the Hadamard's postulates of wellposedness $^{13}$. The estimation of the best $\lambda$ function poses severe numerical difficulties. Pirrong and Jermakyan (2000) restricted $\lambda$ to be a function of $q$ only. They estimated it by regularizing the problem and using the methods of small parameters. In our case, solving PDE is much more time demanding as it contains more dimensions. So, we decided to calibrate a constant $\lambda$. This simplified problem is easier to solve and does not need any regularization. One can see that the results remain interesting.

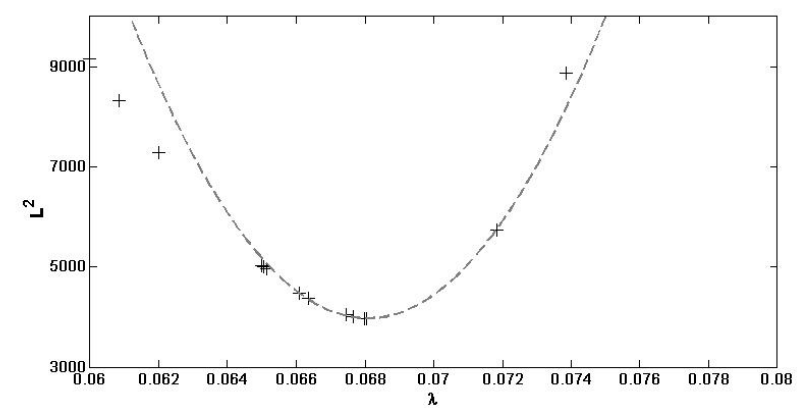

Figure 7: Function values calculated by the optimization algorithm for the September Peak Load contract

The optimization problem (19) is difficult. Firstly the cost of obtaining a function value, that is obtaining the time series of futures value for a particular $\lambda$, is very high. The second difficulty is that the nature of the function $\mathcal{F}$ prevents the computation of any gradient or Hessian, which is a serious drawback for optimization methods. Finally, the function $\mathcal{F}$ is subject to all numerical errors. We select a trust region algorithm that uses quadratic models developed by Conn and Toint (1996) which is well suited for our framework. The idea of this algorithm is to fit the best quadratic interpolation in the set of known function values and then calculate the function where the quadratic model is optimal in the trust-region.

\footnotetext{
${ }^{13}$ The following properties define the Hadamard's condition of well-posedness. For all admissible data, a solution exist. For all admissible data, the solution is unique. The solution depends continuously on the data.

The problem of identification usually violates the last condition which can creates serious numerical problems.
} 


\section{Solution}

We test our model for PeakLoad and Baseload month future with maturity of June and September. Those contracts are traded up to 6 month before maturity, so the number of quotes is approximately 110 . The results are presented in figure (8). The optimization procedure for estimating $\lambda$ requires up to 20 resolutions of the PDE for each contract.
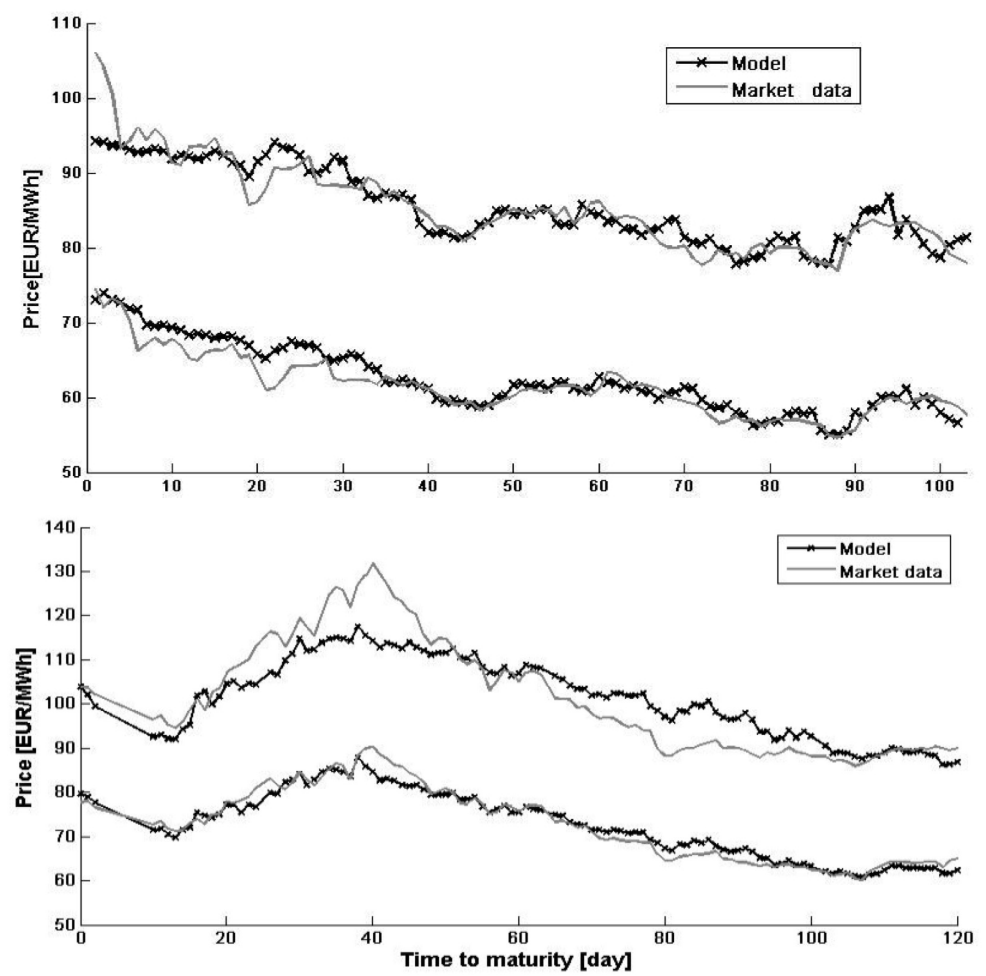

Figure 8: Solution for June (up) and September (down) month future

One can see that the modeled prices fit market data very well. The induced dynamics of the fuel and carbon futures through the marginal cost process appears correct. Table 3 gives the estimated $\lambda$ and the $\mathcal{L}^{2}$ norm of the error for each contracts. One can also observe that $g(\gamma, q, \tau)$ does not vary with load except when time is very close to maturity (i.e. less than 8 days). Current load shocks do not affect futures contracts that are far from maturity. This is due to the strong mean reverting pattern of the load stochastic process. 


\begin{tabular}{|c|c|c|}
\hline Contract & estimated $\lambda$ & Norm of the errors \\
\hline \hline June Baseload & 5.43 & 333.2 \\
June Peakload & -37.48 & 599 \\
September Baseload & 3.75 & 401 \\
September Peakload & -43.94 & 3972 \\
\hline
\end{tabular}

Table 3: Calibration's results of the risk market price for different contracts

One can see that the market price of risk is small and positive for the Baseload contract. It is negative and much more important for the Peakload contract. A positive (respectively negative) market price of risk represents a negative (positive) risk premium. It implies that the buyer of a PeakLoad futures must pay a important risk premium to the seller. Indeed, the difference between the modeled prices and the futures prices obtained by assuming no market price of risk (i.e. $\lambda=0$ ) is high and reach a maximum of 14.81 $€ /$ MWh for the June PeakLoad contract and $25.1 € /$ MWh for the September PeakLoad contract. Surprisingly, such risk premium does not exist for a Baseload contract even though both contracts cover the riskiest hours of the day where the price can jump to extreme values.

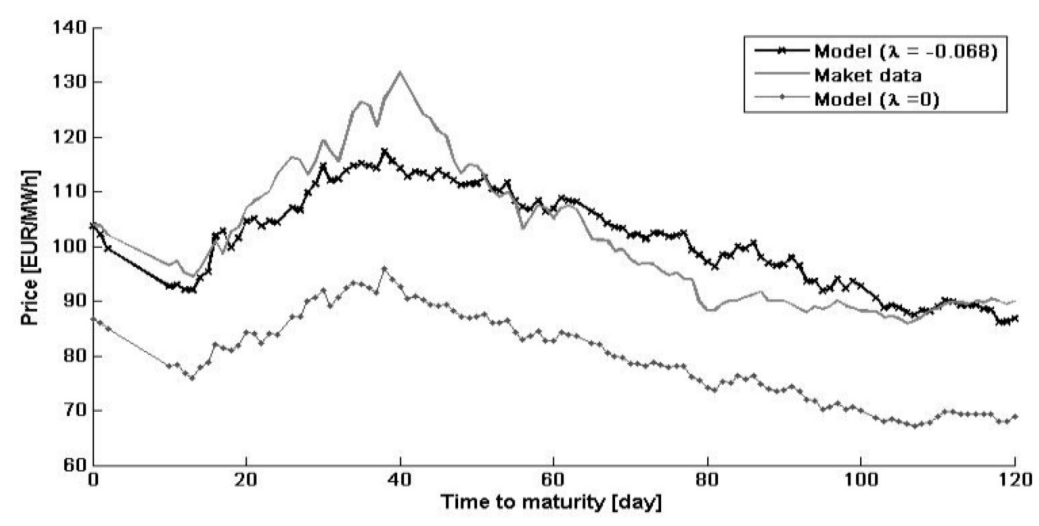

Figure 9: September Peakload contract: future valuation with an without a market price of risk

These results are to some extend contradictory. The difference of market price of risk imply an arbitrage possibility between the 2 contracts, a phenomena that standard finance theory suggest is impossible. This result possibly appears in our model because the marginal cost assumption is not totally valid for the spot market price. As an illustration of this problem, the analysis of von Hirschhausen et al. (2007) found clear divergences between modeled marginal costs and observed market results. For 2004, this difference was $18.5 \%$ on average, and exceeded $30 \%$ for more than $25 \%$ of the time. During off-peak hours, market prices are below the marginal costs and the reason can be attributed to start-up cost and real generators operating constraints that are not taken into account in our simplified unit commitment model. Indeed, it may be less costly for a base unit 
to continue production even if the price is lower than is marginal cost than to shut down during off-peak (nighttime). Actually, from december 2007, the EEX permit negative bids and thus the conclusion of transaction with negative prices.

If such divergences appear in the spot market, it is normal to find them again in the future market. Our model does not capture those effects because we suppose perfectly dispatchable generators. We restrict ourself to this simplest version of the dispatch problem, because the formulation produces a well-defined solution to the energy pricing problem ${ }^{14}$. Finally, the marginal cost assumption permit us to predict the influence of all the state variables on electricity prices. That implied dynamics seems the correct one.

\section{Conclusion}

We present in this paper a new model for the valuation of power future. It is based on the main fundamental factors driving electricity generation. We assume a perfectly competitive market and perfectly dispatchable generators. In that case the price of electricity is the marginal cost of producing the last unit of power. The main factors driving short run marginal cost are the demand, the fuel's price and the carbon price in European countries. We extend the Pirrong-Jermakayan framework to all those variables and finally get a partial differential equation that any power contingent claim must obey. Examining the special structure of marginal cost, we simplify this equation for the futures valuation problem in order to make it computationally tractable. Also, as demand is not a traded asset, this valuation problem contains a market price of risk that has to be estimated from market data.

We test the model and extract the market price of risk of BaseLoad and PeakLoad contract on the German market for June and September 2008. We find that the modeled prices fit quite well the market's data and that marginal cost hypothesis can well reproduce power future dynamics from fuels and carbon prices. Nevertheless, we observe 2 different market prices of risk for Baseload and Peakload. The market price of risk is important for PeakLoad contract while it is almost inexistant for a Baseload contract. This difference implies that there exist arbitrage opportunity in our model. A possible explanation of this contradiction can be found in the computation of the marginal cost that permit us to link the state variables to electricity prices. Indeed in the spot market, we have clear evidence that prices already differ from the computed marginal cost. The reason is that we are neglecting important constraints of electricity generation, like minimum output and start-up cost. Those characteristics are difficult to include because it makes the unit commitment problem harder to solve, and, more importantly, it is not anymore possible to define a price vector that is an equilibrium. Finally, we still find that the marginal cost can capture well the effects of fuel and carbon prices on electricity

\footnotetext{
${ }^{14}$ Indeed, with more general unit commitment problem (that contains non convex production set for generators), it is usually not possible to find "incentive compatible" linear price, meaning that suppliers would want to change the dispatch at that given prices (Gribik et al., 2007).
} 
prices. Future work should try to incorporate the discrete nature of the unit commitment. In this perspective, pricing schemes presented by Gribik et al. (2007) seems a good starting point.

\section{References}

Bessembinder, H., Lemmon, M., 2002. Equilibrium pricing and optimal hedging in electricity forward markets. Journal of Finance 57 (3), 1347-1382.

Bierbrauer, M., Menn, C., Rachev, S. T., Truck, S., 2007. Spot and derivative pricing in the eex power market. Journal of Banking \& Finance 31 (11), 3462-3485.

Bloechlinger, L., 2006. A coherent spot/forward price model with regime-switching. In: Operations Research, Proceedings 2006. pp. 271-278.

Borenstein, S., Bushnell, J. B., Wolak, F. A., December 2002. Measuring market inefficiencies in california's restructured wholesale electricity market. American Economic Review 92 (5), 1376-1405.

Cartea, A., Villaplana, P., 2007. Spot price modeling and the valuation of electricity forward contracts: the role of demand and capacity. Working Papers 0718, Birkbeck, School of Economics, Mathematics \& Statistics.

Conn, A. R., Toint, P. L., 1996. An algorithm using quadratic interpolation for unconstrained derivative free optimization. In: Di Pillo, G., Gianessi, F. (Eds.), Nonlinear Optimization and Applications. Plenum Publishing, pp. $22-47$.

Farnsworth, H., Bass, R., 2003. The term structure with semi-credible targeting. The Journal of Finance $58,839-866(28)$.

Geman, H., Roncoroni, A., 2006. Understanding the fine structure of electricity prices. Journal of Business 79 (3), 1225-1262.

Gribik, P., Hogan, W., Pope, S., 2007. Market-clearing electricity prices and energy uplift. Working paper, Cambridge, Massachussets, Harvard Electricity Policy Group.

Harrison, J. M., Taksar, M. I., 1983. Instantaneous Control of Brownian Motion. Mathematics of Operations Research 8 (3), 439-453.

Huisman, R., Mahieu, R. J., 2003. Regime Jumps in Electricity Prices. Working paper, Rotterdam School of Management.

Lucia, J. J., Schwartz, E., 2002. Electricity prices and power derivatives: Evidence from the nordic power exchange. Review of Derivatives Research 5, 5-50.

Musgens, F., 2006. Quantifying Market Power in the German Wholesale Electricity Market Using a Dynamic Multi-Regional Dispatch Model. Journal of Industrial Economics 54 (4), 471-498.

Pirrong, C., Jermakyan, M., 2000. The Price of Power : The Valuation of Power and Weather Derivatives. Working paper, Washington University, Olin School of Business.

Schwartz, E. S., Smith, J., 2000. Short-term variations and long-term dynamics in commodity prices. Management Science 46 (7), 893-911.

Scott, H., Hogan, W., 2002. Market power and market simulations. Working paper, Cambridge, Massachussets, Harvard Electricity Policy Group.

Swider, D. J., Ellersdorfer, I., Hundt, M., Voss, A., 2007. Anmerkungen zu empirischen analysen der preisbildung am deutschen spotmarkt fur elektrizitat. Tech. rep., University of Stuttgart, Institute of Energy Economics and the Rational Use of Energy.

Villaplana, P., 2003. Pricing Power Derivatives: A Two-Factor Jump-Diffusion Approach. Working paper, Universidad Carlos III, Departamento de Economa de la Empresa.

von Hirschhausen, C., Weigt, H., Zachmann, G., Jan. 2007. Price formation and market power in germany's wholesale electricity markets. Study comissioned by the vik, Dresden University of Technology. 


\section{A. Estimation of the load process}

We estimate the stochastic process of the load using non-parametric techniques, as Pirrong-Jermakayan Pirrong and Jermakyan (2000). We collect the data $\left(t_{i}, Q_{i}\right)_{i=1}^{n}$ for the daily peak load value ${ }^{15}$ (at $12 \mathrm{am}$ ) for 2006-2007 during working day. Ignoring the local time processes $d L_{t}$, the SDE to calibrate is the following geometric OrnsteinUlhenbeck process.

$$
\frac{d q_{t}}{q_{t}}=k\left(\ln \left(q_{t}\right)-\theta_{q}(t)\right) d t+\sigma_{q} d u_{t}
$$

In this SDE, the parameter $\theta_{q}(t)$ is the expected value of the logarithm of the series. We estimate it by fitting a local polynomial to the series for each day $t_{j}$ of the year. The expected value of the $\log$-load $\theta_{q}\left(t_{j}\right)$ at $t_{j}$ is the value of the local polynomial This local polynomial is obtained by minimizing the following function:

$$
\mathcal{R}\left(\theta_{q}\left(t_{j}\right), b_{1} ; t\right)=\sum_{i=1}^{n}\left[\ln \left(Q_{i}\right)-\theta_{q}\left(t_{j}\right)-b_{1} \operatorname{dist}\left(t_{i}, t_{j}\right)\right]^{2} K\left(\frac{\operatorname{dist}\left(t_{i}, t_{j}\right)}{h}\right)
$$

The symbol $\operatorname{dist}\left(t_{i}, t_{j}\right)$ represents the distance between 2 working days. It takes care of the calendar effects of the date. $K(\ldots)$ is a Gaussian probability density. It gives the weight of the different observations for the least square problem. Only the data that are within a bandwidth $h$ of $t_{j}$ have a consequent weight in the minimization problem (21). Finally, once the conditional mean is known, $k$ and $\sigma_{q}$ can be obtained by OLS regressing $\frac{\Delta q_{t}}{q_{t}}$ on $\left(\ln \left(q_{t}\right)-\theta_{q}(t)\right)$.

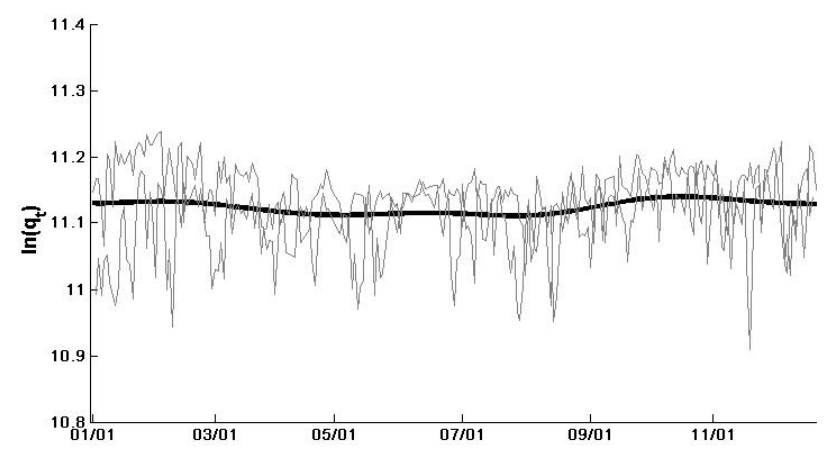

Figure 10: Log load time series and estimated $\theta_{q}(t)$

\footnotetext{
${ }^{15}$ The net load data in Germany comes from the Union of Co-ordination of Transmission of Electricity (www.ucte.org). For the import-export flows, we use data from ETSO (www.etsovista.org). The wind production data are given by the Association of German network operators (www.vdn-berlin.de)
} 


\section{Recent titles \\ CORE Discussion Papers}

2008/60. Yu. NESTEROV. Barrier subgradient method.

2008/61. Thierry BRECHET, Johan EYCKMANS, François GERARD, Philippe MARBAIX, Henry TULKENS and Jean-Pascal VAN YPERSELE. The impact of the unilateral EU commitment on the stability of international climate agreements.

2008/62. Giorgia OGGIONI and Yves SMEERS. Average power contracts can mitigate carbon leakage.

2008/63. Jean-Sébastien TANCREZ, Philippe CHEVALIER and Pierre SEMAL. A tight bound on the throughput of queueing networks with blocking.

2008/64. Nicolas GILLIS and François GLINEUR. Nonnegative factorization and the maximum edge biclique problem.

2008/65. Geir B. ASHEIM, Claude D'ASPREMONT and Kuntal BANERJEE. Generalized timeinvariant overtaking.

2008/66. Jean-François CAULIER, Ana MAULEON and Vincent VANNETELBOSCH. Contractually stable networks.

2008/67. Jean J. GABSZEWICZ, Filomena GARCIA, Joana PAIS and Joana RESENDE. On Gale and Shapley 'College admissions and stability of marriage'.

2008/68. Axel GAUTIER and Anne YVRANDE-BILLON. Contract renewal as an incentive device. An application to the French urban public transport sector.

2008/69. Yuri YATSENKO and Natali HRITONENKO. Discrete-continuous analysis of optimal equipment replacement.

2008/70. Michel JOURNÉE, Yurii NESTEROV, Peter RICHTÁRIK and Rodolphe SEPULCHRE. Generalized power method for sparse principal component analysis.

2008/71. Toshihiro OKUBO and Pierre M. PICARD. Firms' location under taste and demand heterogeneity.

2008/72. Iwan MEIER and Jeroen V.K. ROMBOUTS. Style rotation and performance persistence of mutual funds.

2008/73. Shin-Huei WANG and Christian M. HAFNER. Estimating autocorrelations in the presence of deterministic trends.

2008/74. Yuri YATSENKO and Natali HRITONENKO. Technological breakthroughs and asset replacement.

2008/75. Julio DÁVILA. The taxation of capital returns in overlapping generations economies without financial assets.

2008/76. Giorgia OGGIONI and Yves SMEERS. Equilibrium models for the carbon leakage problem.

2008/77. Jean-François MERTENS and Anna RUBINCHIK. Intergenerational equity and the discount rate for cost-benefit analysis.

2008/78. Claire DUJARDIN and Florence GOFFETTE-NAGOT. Does public housing occupancy increase unemployment?

2008/79. Sandra PONCET, Walter STEINGRESS and Hylke VANDENBUSSCHE. Financial constraints in China: firm-level evidence.

2008/80. Jean GABSZEWICZ, Salome GVETADZE, Didier LAUSSEL and Patrice PIERETTI. Pubic goods' attractiveness and migrations.

2008/81. Karen CRABBE and Hylke VANDENBUSSCHE. Are your firm's taxes set in Warsaw? Spatial tax competition in Europe.

2008/82. Jean-Sébastien TANCREZ, Benoît ROLAND, Jean-Philippe CORDIER and Fouad RIANE. How stochasticity and emergencies disrupt the surgical schedule.

2008/83. Peter RICHTÁRIK. Approximate level method.

2008/84. Çağatay KAYI and Eve RAMAEKERS. Characterizations of Pareto-efficient, fair, and strategyproof allocation rules in queueing problems.

2009/1. Carlo ROSA. Forecasting the direction of policy rate changes: The importance of ECB words.

2009/2. Sébastien LAURENT, Jeroen V.K. ROMBOUTS and Francesco VIOLANTE. Consistent ranking of multivariate volatility models. 


\section{Recent titles}

\section{CORE Discussion Papers - continued}

2009/3. Dunia LÓPEZ-PINTADO and Juan D. MORENO-TERNERO. The principal's dilemma.

2009/4. Jacek B. KRAWCZYK and Oana-Silvia SEREA. A viability theory approach to a two-stage optimal control problem of technology adoption.

2009/5. Jean-François MERTENS and Anna RUBINCHIK. Regularity and stability of equilibria in an overlapping generations model with exogenous growth.

2009/6. Nicolas GILLIS and François GLINEUR. Using underapproximations for sparse nonnegative matrix factorization.

2009/7. Michel M. DENUIT, Louis EECKHOUDT and Mario MENEGATTI. Correlated risks, bivariate utility and optimal choices.

2009/8. Michel M. DENUIT, Louis EECKHOUDT and Mario MENEGATTI. Adding independent risks in an insurance portfolio: which shape for the insurers' preferences?

2009/9. Antoine BOMMIER and Stéphane ZUBER. The Pareto principle of optimal inequality.

2009/10. Raouf BOUCEKKINE, Jacek B. KRAWCZYK and Thomas VALLEE. Environmental negotiations as dynamic games: Why so selfish?

2009/11. Théophile T. AZOMAHOU, Raouf BOUCEKKINE and Phu NGUYEN-VAN. Promoting clean technologies under imperfect competition.

2009/12. Patrice PIERETTI and Skerdilajda ZANAJ. On tax competition, public goods provision and jurisdictions' size.

2009/13. Jeroen V.K. ROMBOUTS and Lars STENTOFT. Bayesian option pricing using mixed normal heteroskedasticity models.

2009/14. Gauthier de MAERE d'AERTRYCKE and Yves SMEERS. The valuation of power futures based on optimal dispatch.

\section{Books}

H. TULKENS (ed.) (2006), Public goods, environmental externalities and fiscal competition. New York, Springer-Verlag.

V. GINSBURGH and D. THROSBY (eds.) (2006), Handbook of the economics of art and culture. Amsterdam, Elsevier.

J. GABSZEWICZ (ed.) (2006), La différenciation des produits. Paris, La découverte.

L. BAUWENS, W. POHLMEIER and D. VEREDAS (eds.) (2008), High frequency financial econometrics: recent developments. Heidelberg, Physica-Verlag.

P. VAN HENTENRYCKE and L. WOLSEY (eds.) (2007), Integration of AI and OR techniques in constraint programming for combinatorial optimization problems. Berlin, Springer.

P-P. COMBES, Th. MAYER and J-F. THISSE (eds.) (2008), Economic geography: the integration of regions and nations. Princeton, Princeton University Press.

J. HINDRIKS (ed.) (2008), Au-delà de Copernic: de la confusion au consensus ? Brussels, Academic and Scientific Publishers.

\section{CORE Lecture Series}

C. GOURIÉROUX and A. MONFORT (1995), Simulation Based Econometric Methods.

A. RUBINSTEIN (1996), Lectures on Modeling Bounded Rationality.

J. RENEGAR (1999), A Mathematical View of Interior-Point Methods in Convex Optimization.

B.D. BERNHEIM and M.D. WHINSTON (1999), Anticompetitive Exclusion and Foreclosure Through Vertical Agreements.

D. BIENSTOCK (2001), Potential function methods for approximately solving linear programming problems: theory and practice.

R. AMIR (2002), Supermodularity and complementarity in economics.

R. WEISMANTEL (2006), Lectures on mixed nonlinear programming. 